\title{
Study on Sewage Purification Effect in Surface Flow Constructed Wetland
}

Xiuli Li $\dagger$

School of Water Conservancy, North China University of Water Resources and Electric Power, Zhengzhou 450045, China

†Corresponding author: lixiuli96@163.com

Nat. Env. \& Poll. Tech.

Website: www.neptjournal.com

Received: $24-10-2019$

Revised: 11-09-2019

Accepted: 16-01-2020

Key Words:

Constructed wetland

Plant community

Surface flow

Sewage purification

\begin{abstract}
The status quo that the shortage of water resources in North China and the arbitrary discharge of sewage in rural areas have led to the deterioration of water environment, which not only aggravates the contradiction between supply and demand of regional water resources but also brings harm to people's life and health. How to properly discharge sewage according to the actual situation in rural areas is a question that needs to be answered urgently. The method adopted in this paper is to build a constructed wetland with low cost and simple operation and maintenance in the study area, and purify the water quality through parallel + multi-stage cascade surface flow constructed wetland system. The results show that the purification effect of the wetland system is acceptable, and the removal rate of each index shows a decreasing trend with time. The larger the area is, and the more plant species there are, the better the removal effect will be. The trend of concentration change along the water flow path of each index is also gradually decreasing, and the decline in the early stage is larger. The method of standard index evaluation is adopted to evaluate water quality purification effect of the wetland system, and all indexes reach the standard. In accordance with the Surface Water Environment Quality Standard (GB3838-2002), after wetland purification, the water quality indexes of COD, $\mathrm{TP}, \mathrm{NH}_{3}-\mathrm{N}$ and $\mathrm{DO}$ all reach Class IV water quality standard, and $\mathrm{BOD}_{5}$ reaches Class II water quality standard. The wetland system effectively reduces the impact of arbitrary sewage discharge on the water environment in rural areas and achieved water quality purification and ecological restoration. The quality of the living environment of local residents is improved. The beautiful environment also promotes people's awareness of protecting wetland ecological environment.
\end{abstract}

\section{INTRODUCTION}

With the development of economy and the improvement of people's living standard, the demands for water resources is increasing, and accordingly, the amount of wastewater and sewage generated is also increasing. Particularly in the economically underdeveloped rural areas, there is no sewage treatment plant, and the domestic sewage generated is discharged directly in the environment. The problem that the water environment is polluted and destroyed by the discharged wastewater and sewage is becoming more and more serious (Zhong et al. 2012, Wan et al. 2016). The pollution of the water environment not only aggravates the crisis of water source shortage but also damages the water ecological environment seriously, which brings challenges to economic development, people's living environment and health. The problem of how to govern the polluted water environment, alleviate the shortage of water resources and return a good living environment to people shall be solved urgently (Zhong et al. 2012). The factors causing water environment damage are more, and governance difficulty is large. To solve those problems, this paper focuses on how to purify polluted water resources, protect and improve the environment, improve people's health level and build an environment-friendly society by constructing constructed wetland system with low cost and simple operation and maintenance.

Constructed wetland is a kind of process to purify sewage through the triple synergy of physical, chemical and biological effects of substrate, plants and microorganisms. When sewage enters into the constructed wetland, its pollutants are adsorbed, filtered and decomposed by beds to purify water quality (Haberl et al. 2003, Vymazal 2007, Zhang 2011). The constructed wetland combines sewage treatment with the ecological environment, which not only purifies water quality effectively but also beautifies the ecological environment and enhances the appreciation of regional ecological landscape (Wu et al. 2010, Zhang et al. 2012, Shi et al. 2017). The constructed wetland has gained more attention and concern of people by its unique multiple-advantages and now is extensively applied to river sewage treatment. The types of constructed wetlands are divided into surface flow, horizontal subsurface flow, vertical subsurface flow and combined flow (Zhang 2011, Chen et al. 2008).

In the surface flow constructed wetland, the sewage flows horizontally from the inlet end of the pool to the outlet end 
without fillers and is purified by wetland plant absorption, rhizome interception and microbial degradation (Tong et al. 2014, Zhao et al. 2018). Surface-flow constructed wetlands have relatively low construction and operational costs but occupy a larger area. In the horizontal subsurface flow constructed wetland, the sewage flows from below the surface of the packing layer and horizontally from the inlet end of the pool to the outlet end. The water quality can be purified by the adsorption and interception of the packing, plant absorption and microbial degradation, which can withstand greater hydraulic load and pollution load (Kato et al. 2010, Czudar 2011). In the vertical subsurface flow constructed wetland, the sewage flows vertically through the filter material layer in the pool. The direction of flow can be from top to bottom or from bottom to top of the packing. It can withstand high pollution load and improve the removal rate of pollutants. The combined flow constructed wetland is generally composed of two or more constructed wetland pools of the same or different types through cascade or parallel mode, etc. The combination mode is usually confirmed according to the actual situation.

The study area is located in the countryside, and the sewage produced by farmers is usually discharged directly and not concentrated. In combination with local actual situation, the surface flow constructed wetland was selected and then constructed to purify the sewage according to the topography, landform and vegetation of the study area. In the long run, surface flow constructed wetland has relatively simple operation and maintenance, long service life, and can create a beautiful natural landscape, providing a good place for people's leisure. In this study, parallel + multi-stage cascade surface flow constructed wetland was selected to treat rural sewage.

\section{MATERIALS AND METHODS}

Overview of the study area: The experimental site of this study is located in the south of Yongnian Wa Flood Storage and Detention Area, Handan City, Hebei Province. The constructed surface flow wetland has an area of 5.33ha. The study area belongs to the warm temperate continental monsoon climate, with four distinct seasons during the year. The annual average temperature is $12.9^{\circ} \mathrm{C}$, the precipitation is about $550 \mathrm{~mm}$, the water surface evaporation is $1240 \mathrm{~mm}$, and the relative humidity is $67 \%$. The spatial and temporal distribution of annual precipitation is extremely uneven. The precipitation from June to September accounts for about $80 \%$ of the annual precipitation, and the characteristics of rainfall are characterized by large and concentrated rainfall. There are many villages and towns in the region. The rural daily domestic sewage, wastewater and sewage from small food enterprises, farmland irrigation recession water and rainwater are all directly discharged to local rivers, forming the sewage source of constructed wetland.

Trial design: The polluted river water was introduced into constructed wetland through diversion canals, and the wetlands are divided into two parts, i.e. No. I and No. II, with diversion canals as the dividing line. The wetland system is comprised of retention wall, guide wall and drop weir. (1) Wetland is separated from the surrounding environment by using water retaining wall to avoid the influence of the surrounding environment on water purification in the test area. (2) The guide wall is built in the wetland to change water flow direction, make full use of wetland area, increase hydraulic retention time, make sewage react fully with wetland, and improve pollutant removal rate. The guide wall guides the water flow to flow forward along the S-shaped way. Respectively, 15-grade and 13-grade (pool) wetland in series connection are arranged in Wetland I and Wetland II. (3) The drop weir is used to add the content of dissolved oxygen in water, and speed up pollutant decomposition by aerobic microorganisms. Totally 9 drop weirs are set in the wetland, respectively four in Wetland I and 5 in Wetland II. (4) Since sewage entering the wetland is mixed with a large amount of household waste, to avoid long-term pollution caused by the waste entered and retained in the test area, the trash rack shall be built on upstream of the diversion canal. (5) According to plant communities of the wetland, the local advantageous plants with the developed root system, favourable purification effect and good stain, freezing and pesticide prevention ability, which are of high economic value and easy to manage shall be selected: reed and lotus flower.

Lotus flowers were planted in 1-4 and 11-12 (Fig.1) in Wetland I, and reeds were planted in the other area; reeds were planted in all areas of Wetland II.

Testing indexes and method: Water quality sampling in the wetlands was conducted from May to November 2018. To reduce errors, the water samples were collected at the same place in the process of sample collection, and collection cycle was as consistent as possible. Moreover, several groups of data were acquired and calculated to get the mean value. One sampling point was set each on inlet and outlet of the wetland, and outlet of Wetland I and Wetland II, and three in Wetland I and Wetland II respectively, totally nine sampling points (Fig. 1). The sampling frequency was twice averagely every month, and totally 14 times were done.

Indicators for testing water samples include $\mathrm{COD}, \mathrm{BOD}_{5}$, $\mathrm{TP}, \mathrm{TN}, \mathrm{NH}_{3}-\mathrm{N}$ and DO. The water quality testing methods can be seen in Table 1 . 


\section{RESULTS AND ANALYSIS}

Continuous monitoring is applied to the purification system of the constructed wetland in nearly 7 months from May 10 to November 5, 2018. During this period, samples are taken twice from the same place every month averagely, and various indexes are detected.

Hydraulic load analysis: The intelligent flow meter was used to monitor daily average flow rate and daily total water flow in the wetland. To guarantee accurate data, the portable flow rate meter is used for verification. The water flow change scope was $10500 \mathrm{~m}^{3} / \mathrm{d} \sim 13100 \mathrm{~m}^{3} / \mathrm{d}$, and average water inlet volume was $11844 \mathrm{~m}^{3} / \mathrm{d}$ in the wetland during the study period from May to November 2018.

The calculation formula for the hydraulic load is:

$$
q_{h s}=Q / A
$$

In the formula: $q_{h s}$ - Surface hydraulic load, $\mathrm{m}^{3} /\left(\mathrm{m}^{2} \cdot \mathrm{d}\right)$;

$\mathrm{Q}$ - Wetland water flow, $\mathrm{m}^{3} / \mathrm{d} ; \mathrm{A}$ - Wetland area, $\mathrm{m}^{2}$

According to calculation formula (1), the wetland hydraulic load change range was $0.15 \sim 0.19 \mathrm{~m}^{3} /\left(\mathrm{m}^{2} \cdot \mathrm{d}\right)$, and the average hydraulic load was $0.17 \mathrm{~m}^{3} /\left(\mathrm{m}^{2} \cdot \mathrm{d}\right)$.
Removal rate analysis: During the study period from May to November 2018, water samples were taken approximately twice a month at a fixed location; totally 14 samples were taken, and each index was tested separately. In accordance with pollutant concentration at the inlet and outlet, the removal rate of each index was calculated. The calculation formula of the removal rate is as follows:

$$
\eta=\frac{C_{0}-C_{e}}{C_{0}} \times 100 \%
$$

In the formula, $\eta$ : pollutant removal rate; $C_{0}$ : inlet pollutant concentration, $\mathrm{mg} / \mathrm{L}$;

$C_{e}$ : outlet pollutant concentration, $\mathrm{mg} / \mathrm{L}$; The pollutant concentration at the inlet and outlet, and the removal rate of each index can be seen in the Figs. 2-6.

According to Figs. 2-6:

(1) The effluent concentration in Wetland I is lower than that of Wetland II when influent concentrations of various indexes are the same. Thus, the purification effect in Wetland I was superior to that in Wetland II. This is because the water area of Wetland I is larger than that of Wetland II; the plants planted in wetland I are lotus

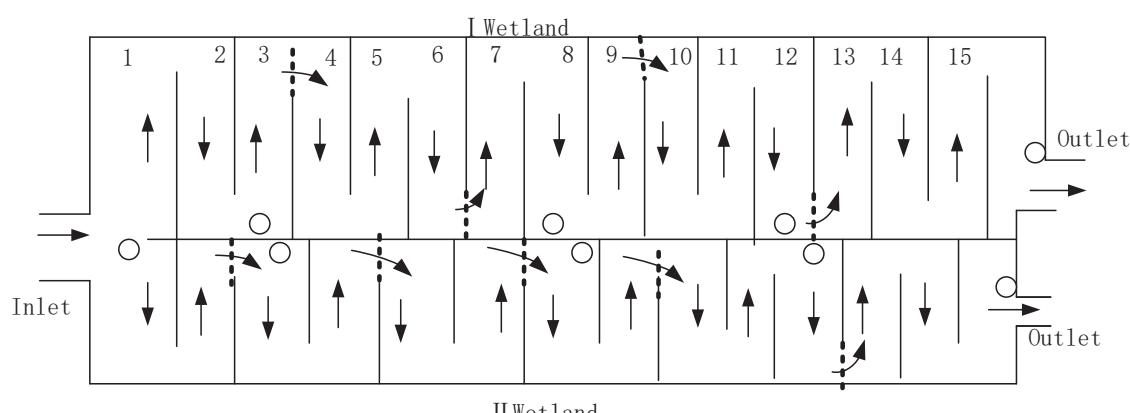

Guide wall __ Drop weir - - S Sampling point $\bigcirc$ Water flow direction

Fig. 1: Layout plan of surface flow constructed wetland.

Table 1: Water quality testing items and methods.

\begin{tabular}{|ll|}
\hline Testing item & Testing method \\
\hline Chemical oxygen demand $(\mathrm{COD})$ & Dichromate method \\
Five-day biochemical oxygen demand $\left(\mathrm{BOD}_{5}\right)$ & Dilution and inoculation test \\
Total phosphorus $(\mathrm{TP})$ & Ammonium molybdate spectrophotometric method \\
Total nitrogen $(\mathrm{TN})$ & Alkaline potassium persulfate digestion-UV spectrophotometric method \\
Ammonia-nitrogen $\left(\mathrm{NH}_{3}-\mathrm{N}\right)$ & Nessler's reagent spectrophotometry \\
Dissolved oxygen $(\mathrm{DO})$ & Iodometry \\
\hline
\end{tabular}




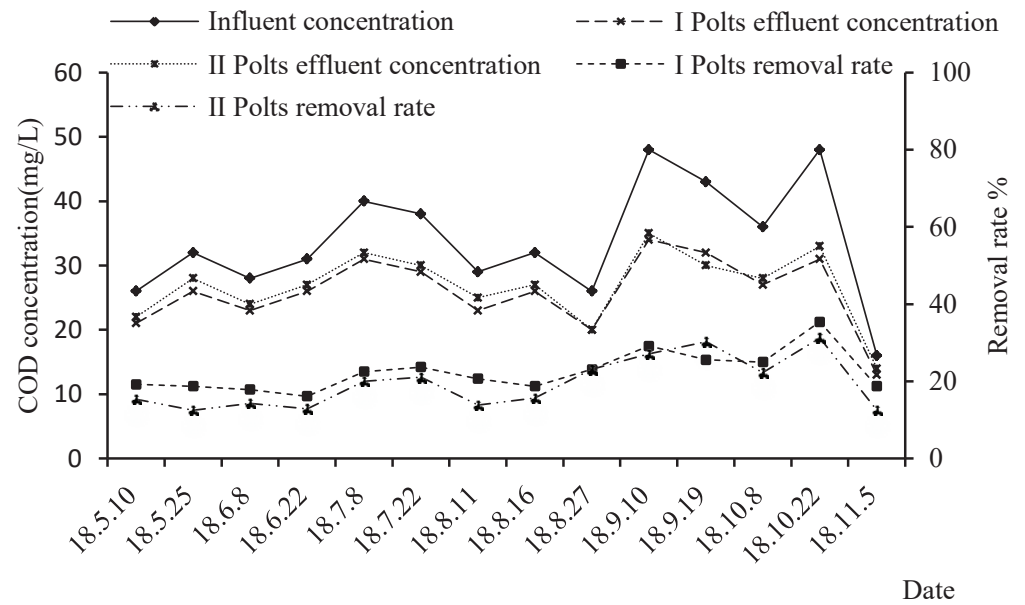

Fig. 2: Inlet and outlet pollutant concentration, and average removal rate of COD on different dates.

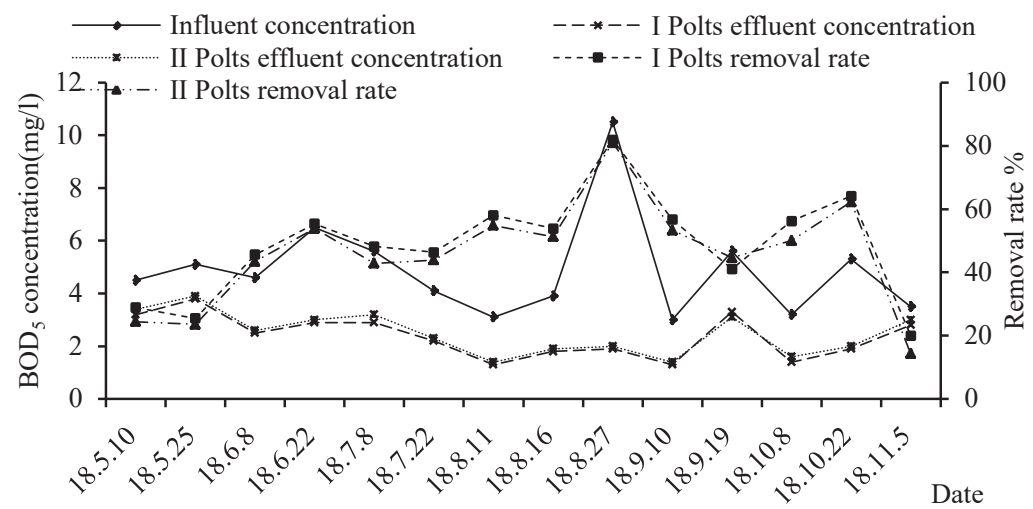

Fig. 3: Inlet and outlet pollutant concentration, and average removal rate of BOD5 on different dates.

dates.

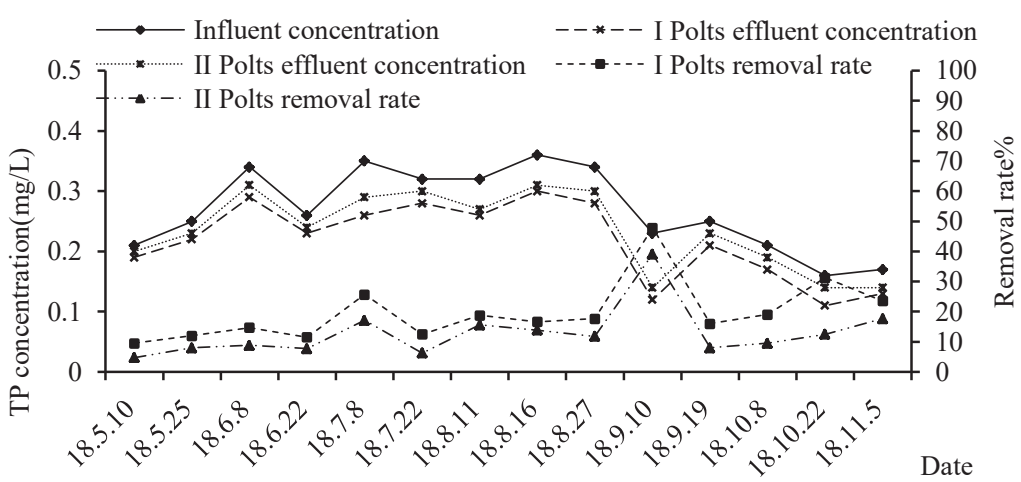

Fig. 4: Inlet and outlet pollutant concentration, and average removal rate of TP on different dates. 


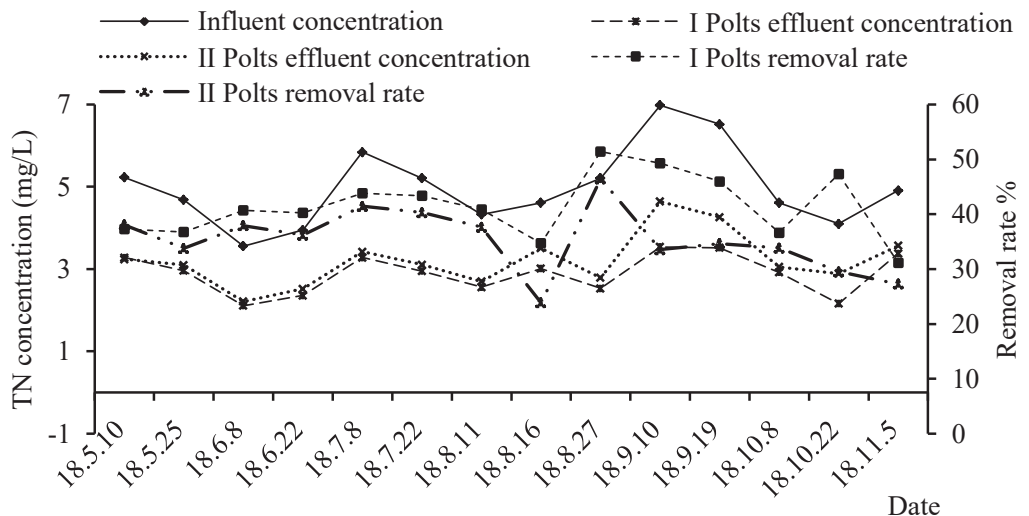

Fig. 5: Inlet and outlet pollutant concentration, and average removal rate of TN on different dates.

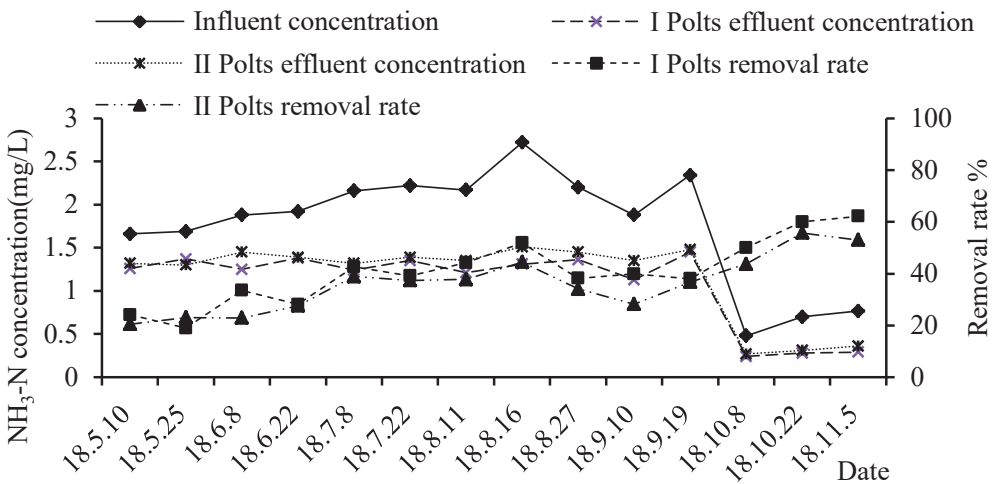

Fig. 6: Inlet and outlet pollutant concentration, and average removal rate of $\mathrm{NH}_{3}-\mathrm{N}$ on different dates.

flower and reeds, and the plants planted in wetland II are reeds. It can be concluded that the size of water area affects the purification effect, and in large area, the sewage stays a longer time and the purification effect is better; different plants have different purification effects on sewage; the mixed plantation of lotus and reeds has better than plantation of reeds.

(2) Due to different areas and different aquatic plants in Wetland I and Wetland II, the removal rates of various testing indexes in the two areas are different. The mean removal rates of $\mathrm{COD}, \mathrm{BOD}_{5}, \mathrm{TP}, \mathrm{TN}$ and $\mathrm{NH}_{3}-\mathrm{N}$ are respectively $22.5 \%, 48.7 \%, 19.8 \%, 41.5 \%$ and $40.8 \%$ in Wetland I, and $19.4 \%, 46 \%, 12.9 \%, 35.3 \%$ and $36 \%$ in Wetland II. In general, the relationship between influent concentration and removal rate is consistent; when the influent concentration is high, the removal rate is higher accordingly.

(3) TP is removed through plant absorption in surface flow constructed wetland. Results show although the removal rate in Wetland I is slightly higher than that in Wetland II, the removal rate of TP in both Wetland I and Wetland II is not favourable. The higher removal rate in Wetland I is because Wetland I plants lotus flowers while Wetland II does not. The plants may absorb a certain amount of TP during growth and metabolic process, and absorb small molecular phosphate-contained substances in sewage through roots and synthesize to plant structure. However, the phosphate absorption function of plants does not contribute much to TP removal in constructed wetland, and the main approach is substrate's absorption of TP in the wetland. It is not effective for surface low constructed wetland to remove TP relying on plants.

(4) The removal rate of TN reaches the highest in August, and the removal rate is higher in Wetland I than Wetland II. It probably relates to DO concentration in the wetland system. The constructed wetland mainly removes nitrogen in the water body through nitrification and denitrification of microorganism, and the anabolism of 
plants (Zhu et al. 2010, Yu et al. 2013). The main content in $\mathrm{TN}$ is $\mathrm{NO}_{3}-\mathrm{N}$. When DO concentration is reduced, it will help the denitrification of nitrate nitrogen. The area of Wetland I is large, and higher biomass requires more DO than that of Wetland II, leading to possible internal oxygen deficiency in the system; more $\mathrm{NO}_{3}-\mathrm{N}$ is converted and TN removal rate is rising.

(5) The removal trends of $\mathrm{NH}_{3}-\mathrm{N}$ in Wetland I and Wetland II are largely consistent. Before August, the removal rate of $\mathrm{NH}_{3}-\mathrm{N}$ is increasing; in September, due to impact of water conditions and microorganism activities, the removal rate is reduced; the removal rate of $\mathrm{NH}_{3}-\mathrm{N}$ in October and November is increased continuously, probably because of smaller $\mathrm{NH}_{3}-\mathrm{N}$ concentration in the water flowing in.

(6) The COD removal situations in Wetland I and Wetland II can be seen in the figure. From May to November, COD is removed to certain degree, and the removal rate in September and October is higher. It is related to COD concentration of water flowing in. When in-flow water COD concentration is high, the removal rate is rising accordingly.

(7) The purification effect of $\mathrm{BOD}_{5}$ in Wetland I and Wetland II is better, and $\mathrm{BOD}_{5}$ removal rate is higher from May to October, and in November is low. The removal rate of $\mathrm{BOD}_{5}$ is related to in-flow water concentration and wetland temperature. According to $\mathrm{BOD}_{5}$ removal rate changes, in the study stage, there are no obvious rules for $\mathrm{BOD}_{5}$ removal rate.

Analysis of the change of water quality indicators along the water flow path: In order to analyse the variation of indexes along the water flow path in the wetland, sampling points were set respectively along Wetland I and II. The sampling points in Wetland I are the inlet point, 1\#, 2\#, 3\#, and outlet point; sampling points in Wetland II are the inlet point, 1\#, 2\#, 3\#, and outlet point; the inlet sampling point of Wetland I and Wetland II is the same. Samples were made totally 7 times on the sampling points set along the two wetlands in the beginning of every month from May to November. After water sample testing and analysis, the changes in various indexes along the water flow path were basically consistent in Wetland I and II. Thus, due to space limitation, this paper only analyses rules of indexes changes along Wetland I. The index changes along the water flow path can be seen in the Figs. 7-11.

According to Figs. 7-11.

(1) The change of COD along the water flow path: Since the in-flow water quality in the wetland is affected by agricultural or domestic pollution, the change in in-flow water concentration every month is large. COD concentration turns smaller along the water flow path. When in-flow water concentration is high, the corresponding concentration downtrend will be more obvious.

(2) The change of $\mathrm{BOD}_{5}$ along the water flow path: The concentration of $\mathrm{BOD}_{5}$ decrease gradually except in September and November. Since the in-flow water $\mathrm{BOD}_{5}$ concentration is smaller in September, there is no removal effect in the wetland; while $\mathrm{BOD}_{5}$ concentration in November is increased other than decreased probably due to impact of temperature.

(3) The change of TP along the water flow path: The concentration of TP show a downward trend along the water flow path, indicating that wetland has a good removal effect on TP. Particularly in August and September, the prosperous plants in the wetland have more obvious absorption effect for phosphate, so that TP concentration along the water flow path is more obvious in August and September than that in other months.

(4) The change of TN along the water flow path: The concentration of TP is decreasing along the water flowing direction in the wetland, particularly obvious in the front end of the wetland. Probably due to larger organic content in the front end, and suitable $\mathrm{C} / \mathrm{N}$ proportion is good for the growth of denitrifying bacteria to improve $\mathrm{TN}$ removal effect.

(5) The change of $\mathrm{NH}_{3}-\mathrm{N}$ along the water flow path: $\mathrm{NH}_{3}-\mathrm{N}$ concentration shows a downtrend along the water flowing direction of the wetland. Moreover, when the $\mathrm{NH}_{3}-\mathrm{N}$ concentration in in-flow water is high, the decreasing trend is more obvious. The decrease of $\mathrm{NH}_{3}-\mathrm{N}$ concentration is caused by microorganism ammonization, and also absorption effect of wetland plants. Higher $\mathrm{NH}_{3}-\mathrm{N}$ concentration makes their effects more remarkable.

Evaluation and analysis: According to monitoring data in the study area, the standard index evaluation method was adopted to evaluate water quality purification effect in the wetland system. The results could distinctly and visually show purification situations along the water flow path and main pollution factors.

The calculation formula for standard index $S_{i j}$ of water quality parameter $i$ on $j$ point is:

$$
S_{i j}=\frac{C_{i j}}{C_{s i}}
$$

In the formula, $S_{i j}$ - Standard index of water quality parameter $i$ on $j$ point 


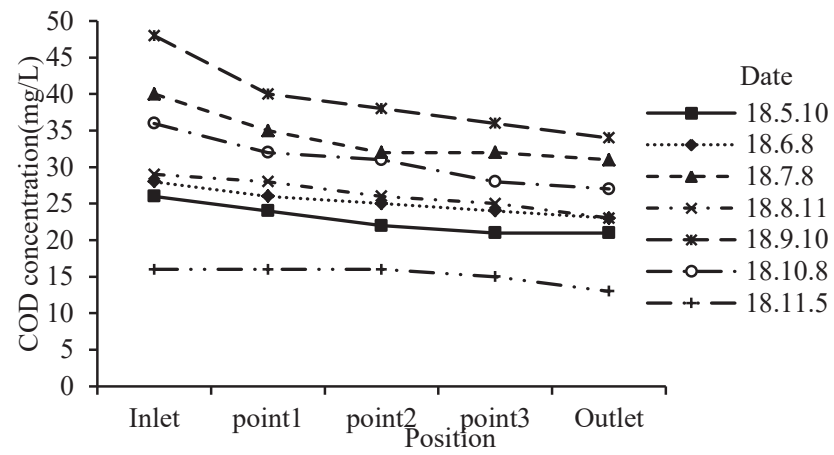

Fig. 7: The change of COD along the water flow path.

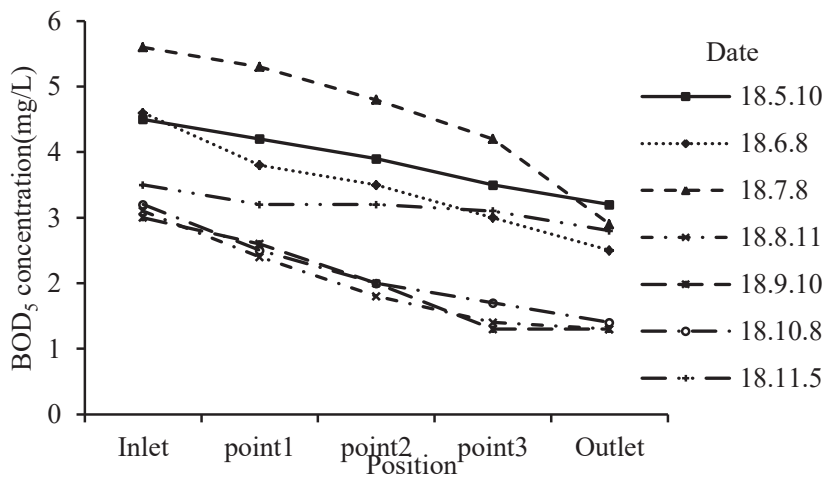

Fig. 8: The change of $\mathrm{BOD}_{5}$ along the water flow path.

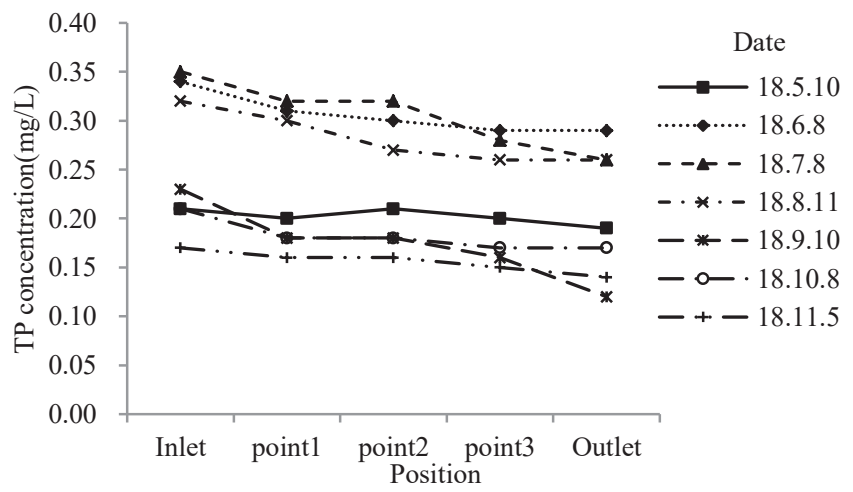

Fig. 9: The change of TP along the water flow path. 


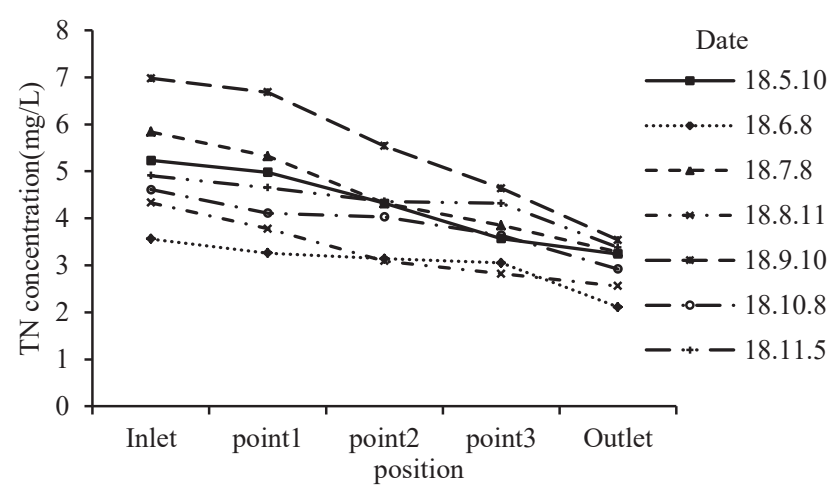

Fig.10: The change of TN along the water flow path.

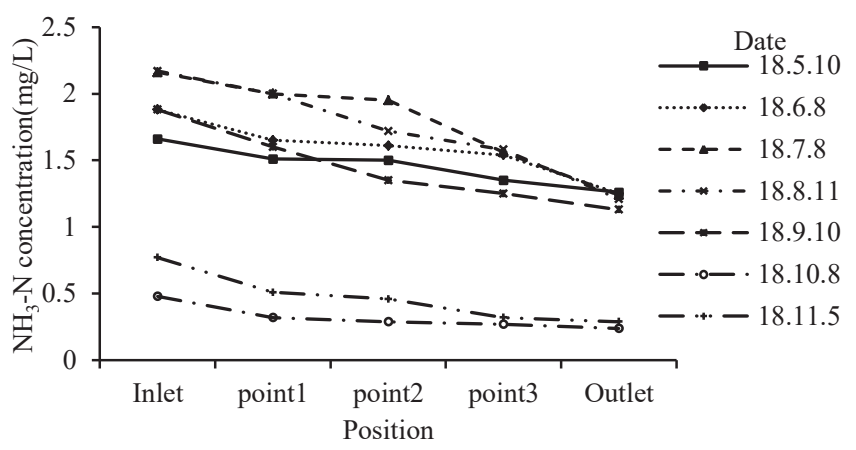

Fig.11: The change of $\mathrm{NH}_{3}-\mathrm{N}$ along the water flow path.

$C_{i j}$ - Concentration of water quality parameter $i$ on $j$ point, $\mathrm{mg} / \mathrm{L}$

$C_{s i}$ - Standard value of water quality parameter $i$ point, $\mathrm{mg} / \mathrm{L}$

The single factor evaluation index of each index along the water flow path can be acquired, referring to Table 2 . The calculation results of single factor evaluation indexes in the table were analysed. If the result is smaller than 1 , the water quality reaches the standard, while if the result is larger than 1 , the water quality is out of limit.
The table shows the single factor index of DO, TP, $\mathrm{NH}_{3}-\mathrm{N}, \mathrm{COD}$ and $\mathrm{BOD}_{5}$ in out-flow water of Wetland I and Wetland II is largely smaller than 1 , reaching the water quality standard; single factory index of TN is larger than 1 , and water quality is out of limit. As a whole, each single factor evaluation index shows a downtrend with the movement of purified water flow during wetland purification. It means pollutants are effectively removed along the water flow path, and water quality becomes better gradually.

In line with Surface Water Environment Quality Standard

Table 2: Single factor evaluation index of each index along the water flow path.

\begin{tabular}{|llll|}
\hline Evaluation index & Water inlet & Water outlet in Wetland I & Water outlet in Wetland II \\
\hline DO & 0.78 & 0.77 & 0.86 \\
$\mathrm{TP}$ & 0.9 & 0.73 & 0.8 \\
$\mathrm{TN}$ & 3.32 & 2.04 & 2.11 \\
$\mathrm{NH}$ & $-\mathrm{N}$ & 0.72 & 0.81 \\
$\mathrm{COD}$ & 1.18 & 0.87 & 0.93 \\
$\mathrm{BOD}_{5}$ & 1.13 & 0.4 & 0.35 \\
\hline
\end{tabular}


Table 3: Water quality classification of inlet and outlet water of main indexes from May to Nov 2018.

\begin{tabular}{|c|c|c|c|c|c|c|}
\hline \multirow{2}{*}{$\begin{array}{l}\text { Water quality } \\
\text { Index }\end{array}$} & \multicolumn{2}{|c|}{ Inlet } & \multicolumn{2}{|c|}{ Wetland I } & \multicolumn{2}{|c|}{ Wetland II } \\
\hline & $\begin{array}{l}\text { Mean value } \\
(\mathrm{mg} / \mathrm{L})\end{array}$ & $\begin{array}{l}\text { Water quality } \\
\text { Class }\end{array}$ & $\begin{array}{l}\text { Outlet mean value } \\
(\mathrm{mg} / \mathrm{L})\end{array}$ & $\begin{array}{l}\text { Water quality } \\
\text { Class }\end{array}$ & $\begin{array}{l}\text { Outlet mean value } \\
(\mathrm{mg} / \mathrm{L})\end{array}$ & $\begin{array}{l}\text { Water quality } \\
\text { Class }\end{array}$ \\
\hline COD & 33.8 & V & 26 & IV & 27.8 & IV \\
\hline $\mathrm{BOD}_{5}$ & 4.7 & IV & 2.4 & II & 2.4 & II \\
\hline $\mathrm{TP}$ & 0.27 & IV & 0.22 & IV & 0.24 & IV \\
\hline $\mathrm{NH}_{3}-\mathrm{N}$ & 1.77 & V & 1.08 & IV & 1.22 & IV \\
\hline DO & 5 & III & 5.1 & III & 4.3 & IV \\
\hline
\end{tabular}

(GB3838-2002), the water quality class of DO, $\mathrm{TP}, \mathrm{NH}_{3}-\mathrm{N}$, $\mathrm{COD}$ and $\mathrm{BOD}_{5}$ at inlet and outlet can be seen in Table 3 . According to the table, after wetland purification, the outlet water quality index $\mathrm{COD}, \mathrm{TP}, \mathrm{NH}_{3}-\mathrm{N}$ and $\mathrm{DO}$ all reach Class IV water quality standard, and $\mathrm{BOD}_{5}$ reaches Class II water quality standard.

\section{CONCLUSION}

In accordance with the observation data of the wetland in nearly one year, the purification effect, concentration changes along the constructed wetland and purification indexes were evaluated and analysed. Results show that the sewage purification effect in parallel + multi-stage cascade surface constructed wetland is favourable. According to aforesaid results:

(1) The mean removal rates of $\mathrm{COD}, \mathrm{BOD}_{5}, \mathrm{TP}, \mathrm{TN}$ and $\mathrm{NH}_{3}-\mathrm{N}$ in the wetland are respectively $22.5 \%, 48.7 \%$, $19.8 \%, 41.5 \%$ and $40.8 \%$ in Wetland I, and $19.4 \%$, $46 \%, 12.9 \%, 35.3 \%$ and $36 \%$ in Wetland II, effectively reducing and eliminating hazards of domestic sewage discharge to the external water body. The size of wetland area and plants varieties affect sewage purification to a certain degree because different types of plants have different absorption functions for various pollutants; the area sizes cause different courses of sewage along the water flow path. Therefore, to improve wetland purification effect, further tests shall try to add sewage course area along the wetland when the wetland area is fixed, and select plants with strong absorption effect to improve the removal rate.

(2) The factors affecting concentration changes of indexes along the water flow path are more; for instance, the in-flow water concentration, temperature and plants and microorganisms in the wetland affect concentration along the water flow path to a certain degree. The concentration of all indexes is decreasing along the water flow path, and the decrease is fast in the front end of the wetland system.
(3) The analysis on water quality after purification according to standard index evaluation method shows that DO, $\mathrm{TP}, \mathrm{NH}_{3}-\mathrm{N}, \mathrm{COD}$ and $\mathrm{BOD}_{5}$ all reach the water quality standards; single factory index of TN is larger than 1 , and water quality is out of limit.

Wetland treatment effect: $\mathrm{NH}_{3}-\mathrm{N}>\mathrm{TN}>\mathrm{BOD}_{5}>\mathrm{COD}>\mathrm{TP}$. In line with Surface Water Environment Quality Standard (GB3838-2002), the outlet water quality index of COD, TP, $\mathrm{NH}_{3}-\mathrm{N}$ and DO, all reach Class IV water quality standard, and $\mathrm{BOD}_{5}$ reaches Class II water quality standard. Although TN outflow water does not reach Class IV class quality standard for lakes and reservoirs, the average removal rate is high, and the removal effect is obvious.

Surface flow constructed wetland has relatively simple operation and maintenance and long service life. Moreover, the plants such as lotus flowers and reeds planted in the wetland not only have ornamental value but also have certain economic value. They could improve the water environment while creating a beautiful natural landscape. Therefore, the surface flow constructed wetland built in rural area with a relatively backward economy can not only achieve water quality purification and ecological restoration but also improve the quality of local residents' living environment. The beautiful environment also promotes people's awareness of wetland ecological environment protection.

\section{REFERENCES}

Chen, Jinjun, Zheng, Chong and Zheng, Shaokui 2008. Pollutant purification performance of a surface flow constructed wetland planted with different aquatic macrophytes and their combination. Acta Scientiae Circumstantiae, 28(10): 2029-2035.

Czudar, A., Gyulai, I., Keresztúri, P., Csatári, I., Serra-Páka, S. and Lakatos, G. 2011. Removal of organic material and plant nutrients in a constructed wetland for petrochemical wastewater treatment. Studia Universitatis Vasile Goldis. Seria Stiintele Vietii, (21): 109-114.

Haberl, R., Grego, S., Langergraber, G., Kadlec, R.H., Cicalini, A.R., Dias, S.M., Novais, J.M., Aubert, S., Gerth, A., Thomas, H. and Hebner, A. 2003. Constructed wetlands for the treatment of organic pollutants. Soils Sediments, 3: 109-124. 
Kato, K., Inoue, T., Ietsugu, H., Koba, T., Sasaki, H., Miyaji, N., Yokota, T., Sharma, P.K., Kitagawa, K. and Nagasawa, T. 2010. Design and performance of hybrid reed bed systems for treating high content wastewater in the cold climate. In: Masi, F., Nivala, J. (Eds), Proceeding of the 12th International Conference Wetland Systems for Water Pollution Control, IWA, IRIDRA Srl and Pan Srl Padova, Italy, 511-517.

Shi, Xinhui, Shuxia Xu, Yanshuo Pan, Youjing Wang, Jiran Zhang, Kun Wu and Shimin Zhang 2017. Effects of urban constructed wetland on water purification efficacy for artificial lake. Journal of Henan Agricultural University, 51(6): 855-859.

Tong, X., Wang, X., He, X. and Kong, H. 2014. Ammonia nitrogen removal and analysis of the ammonia-oxidizing bacterial community in horizontal subsurface flow constructed wetlands. Research of Environmental Sciences, 27(2): 218-224.

Vymazal, J. 2007. Removal of nutrients in various types of constructed wetlands. Science of the Total Environment, 380(1-3SI): 48-65.

Wan, Yun-wen, Gou, Chang-qiang, Mao, Zhi, Li, Xin-jian, Cui, Yuan-lai and Zhao, Shu-jun. 2016. Sewage purification effect of multi-series surface flow constructed wetland. Transactions of Chinese Society of Agricultural Engineering, 32(3): 220-227.

Wu, C.Y., Liu, J.K., Cheng, S.H., Surampalli, D.E., Chen, C.W. and Kao,
C.M. 2010. Constructed wetland for water quality improvement: a case study from Taiwan. Water Science \& Technology, 62(10): 2408.

Yu, Junbao, Hou, Xiaokai and Han, Guangxuan 2013. Removal efficiency of multi-medium constructed wetlands on nitrogen and phosphorus in domestic sewage. Wetland Science, 11(2): 233-239.

Zhang, Qing 2011. Construction and application of constructed wetlands. Wetland Science, 9(4): 373-379.

Zhang, Y.R., Wang, R.Q., Zhang, J. and Liu, J. 2012. Evaluation of ecosystem sustainability for large-scale constructed wetlands. Acta Ecologica Sinica, 32(15): 4803-4810.

Zhao, Zhichao and Zhang, Weitang 2018. BCO-constructed wetland treatment of domestic sewage under normal and low temperatures. Journal of Water Resources \& Water Engineering. 29(5): 28-34.

Zhong, Lin, Zheng, lei, Ding, Ai-zhong and Chen, De-sheng. 2012. Reconstructed wetlands to treat polluted river-pollutant removal efficiency in China. Journal of Beijing Normal University (Natural Science), 48(1): 66-72.

Zhu, G., Jetten, M.S., Kuschk, P., Ettwig, K.F. and Yin, C. 2010. Potential roles of anaerobic ammonium and methane oxidation in the nitrogen cycle of wetland ecosystems. Applied Microbiology and Biotechnology. 86(4): 1043-1055. 